\title{
Double closure repair of mitral paravalvular leak by way of right thoracotomy
}

\author{
Shinsuke Kotani, MD, Koji Hattori, MD, Yasuyuki Kato, MD, and Toshihiko Shibata, MD, Osaka, Japan
}

Paravalvular leak (PVL) occurs in up to $12.5 \%$ of mitral valve replacements (MVRs) ${ }^{1}$ and sometimes recurs. Although various techniques to repair such leaks have been described, ${ }^{2-4}$ surgical intervention for patients undergoing multiple repeat surgery poses a formidable challenge. For the purposes of good exposure and durable repair of mitral PVL, we describe a double closure technique with pledgeted sutures and a pericardial patch using right thoracotomy. This technique might provide greater durability of the repair site and good exposure of the mitral valve.

\section{TECHNIQUE}

The patient is placed in the supine position. A right anterolateral thoracotomy is performed through the fourth intercostal space. Cardiopulmonary bypass is established by arterial cannulation by way of the right femoral artery and venous cannulation by way of the right femoral vein and superior vena cava. The perfusion temperature is stabilized at $25^{\circ} \mathrm{C}$. Ventricular fibrillation is induced by hypothermia. A left atrial vent is inserted through the right superior pulmonary vein. The left atrium is opened from the right side to expose the mitral valve. First, to close the leak directly, pledget-supported braided polyester sutures are placed through the atrial wall to a sewing ring with a pledget on the atrial side (Figure 1, $A$ ). The sutures are brought directly to the pericardial patch and tied together (Figure 1, B). Second, to reinforce the repair site, both ends of the sutures are passed through the left atrium and the patch using a continuous suture technique. The repair site, including the pledgets, is covered with the pericardial patch (Figure 1,C). The stitches should not be placed too deeply to avoid damage to the underlying circumflex coronary artery. After defibrillation with an external paddle, disappearance of the leak is confirmed by direct vision.

\footnotetext{
From the Department of Cardiovascular Surgery, Osaka City General Hospital, Osaka, Japan

Disclosures: Authors have nothing to disclose with regard to commercial support.

Received for publication Oct 13, 2011; revisions received Oct 26, 2011; accepted for publication Nov 8, 2011; available ahead of print Dec 12, 2011.

Address for reprints: Shinsuke Kotani, MD, Department of Cardiovascular Surgery, Osaka City General Hospital, 2-13-22 Miyakojima-Hondori, Miyakojima, Osaka 534-0021 Japan (E-mail: m1155424@med.osaka-cu.ac.jp).

J Thorac Cardiovasc Surg 2012;143:1452-3

$0022-5223 / \$ 36.00$

Copyright (C) 2012 by The American Association for Thoracic Surgery

doi:10.1016/j.jtcvs.2011.11.010
}

We performed this operation for 2 patients with mitral PVL after multiple MVRs. The first patient was an 81-year-old man who underwent MVR for rheumatic mitral regurgitation at age 54 years, and repeat MVR for PVL and aortic valve replacement for rheumatic aortic regurgitation at age 78 years with bioprosthetic valves. He was referred for congestive heart failure and hemolytic anemia. Transesophageal echocardiography revealed PVL at the 9-o'clock position of the mitral prosthetic valve. The leak was repaired with 4 pledgeted mattress sutures and a pericardial patch. The second patient was a 69 -year-old man who underwent aortic valve replacement and MVR for rheumatic valve disease at age 47 years. He underwent a second aortic valve replacement and MVR with mechanical valves for PVLs at age 61 years. He had congestive heart failure and had PVLs at the 2- and 8-o'clock positions of the mitral prosthetic valve. The PVLs were repaired in similar manners. Eight pledgeted mattress sutures were placed from the 2- to 8-o'clock positions to seal both leaks. The pericardial patch covered the closure site, including all the pledgets. Both patients were doing well without PVL or mitral regurgitation after 2 years postoperatively.

\section{DISCUSSION}

We prefer a right thoracotomy approach with cardiopulmonary bypass on ventricular fibrillation for patients
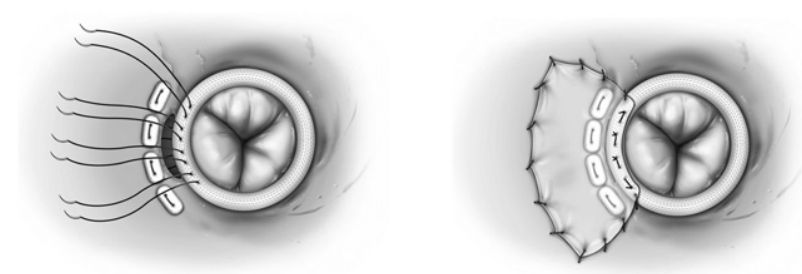

A

C

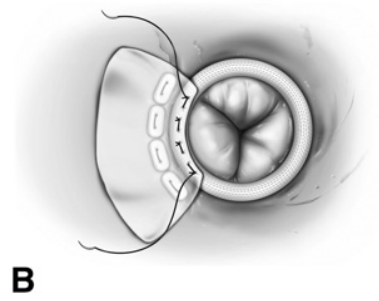

FIGURE 1. A, The pledgeted sutures are placed through the atrial wall to the sewing ring. B, The sutures are brought directly to the pericardial patch, and tied together. $\mathrm{C}$, The repair site, including the pledgets, is covered with the pericardial patch using both ends of the sutures. 
undergoing multiple redo mitral valve surgery. A right thoracotomy requires minimal retraction and dissection of the heart and provides good exposure of the mitral valve. Cardiopulmonary bypass on ventricular fibrillation can decrease the manipulation of the aorta without aortic cannulation and cross-clamps. The disadvantage of this approach is the increased risk of cerebral vascular insufficiency. ${ }^{5}$ Femoral arterial cannulation can cause stroke if the aorta has atherosclerotic changes. When the femoral artery is unavailable, arterial cannulation can be achieved using the right subclavian artery. Because air embolism is also a cause of stroke, vent placement across the aortic root and carbon dioxide flooding of the thoracic cavity are recommended to remove air from the heart. The repeat leak incidence after surgical treatment of mitral PVL has been reported to be $22 \%{ }^{1}$ For PVL repair without repeat replacement, the leak size and location should be defined accurately by preoperative transesophageal echocardiography. In the present cases, we decided that their PVLs could be treated using this technique because of the small leak size and number. If the size is large or multiple leaks are present, repeat MVR might be adequate for PVL treatment. A durable repair technique is also necessary for PVL closure. We present a double-closure technique for mitral PVL repair with both pledgeted sutures and a pericardial patch that might provide greater durability. Even if the mitral annulus becomes detached from the sewing ring, the patch will prevent recurrence of the leak. This technique provides an easy approach to the mitral valve, with durable repair of the leak and is 1 of the feasible options for patients undergoing surgery for mitral PVL.

\section{References}

1. Genoni M, Franzen D, Vogt P, Seifert B, Jenni R, Künzli A, et al. Paravalvular leakage after mitral valve replacement: improved long-term survival with aggressive surgery? Eur J Cardiothorac Surg. 2000;17:14-9.

2. Mangi AA, Torchiana DF. A technique for repair of mitral paravalvular leak. J Thorac Cardiovasc Surg. 2004;128:771-2.

3. Al Halees Z. An additional maneuver to repair mitral paravalvular leak. Eur J Cardiothorac Surg. 2011;39:410-1.

4. Ryomoto M, Mitsuno M, Fukui S, Miyamoto Y. Repair of perivalvular leakage without re-replacement of prosthetic valves. Eur J Cardiothorac Surg. 2011;40:525-6.

5. Svensson LG, Gillinov AM, Blackstone EH, Houghtaling PL, Kim K-H, Pettersson GB, et al. Does right thoracotomy increase the risk of mitral valve reoperation? J Thorac Cardiovasc Surg. 2007;134:677-82.

\title{
Transaortic balloon-expandable aortic valve implantation
}

\author{
Gino Gerosa, MD, ${ }^{\mathrm{a}}$ Assunta Fabozzo, MD, ${ }^{\mathrm{a}}$ Roberto Bianco, MD, ${ }^{\mathrm{a}}$ Giuseppe Tarantini, MD, ${ }^{\mathrm{b}}$ and \\ Augusto D'Onofrio, MD, ${ }^{\mathrm{a}}$ Padova, Italy
}

In patients with severe symptomatic aortic valve stenosis who are inoperable or at high risk for surgical aortic valve replacement, transcatheter aortic valve implantation (TAVI) represents an alternative therapeutic strategy. ${ }^{1} \mathrm{Cur}-$ rently, there are 2 commercially available devices: the selfexpandable CoreValve revalving system (Medtronic Inc, Minneapolis, Minn) and the balloon-expandable Sapien XT valve (Edwards Lifesciences, Irvine, Calif). For the latter, a transapical approach is the first choice in case of unavailable femoral access. However, in patients with severe left ventricular (LV) dysfunction, a surgical approach of the apex can potentially further worsen heart contractility, and the presence of an LV aneurysm with mural thrombi

\footnotetext{
From the Divisions of Cardiac Surgery, ${ }^{\mathrm{a}}$ and Cardiology, ${ }^{\mathrm{b}}$ University of Padova, Italy. Disclosures: Authors have nothing to disclose with regard to commercial support.

Received for publication June 17, 2011; revisions received Nov 17, 2011; accepted for publication Dec 6, 2011; available ahead of print Dec 19, 2011.

Address for reprints: Augusto D'Onofrio, MD, Division of Cardiac Surgery, University of Padova, via Giustiniani 2, CAP 35128, Padova, Italy (E-mail: adonofrio@ hotmail.it).

J Thorac Cardiovasc Surg 2012;143:1453-5

0022-5223/\$36.00

Copyright (C) 2012 by The American Association for Thoracic Surgery doi:10.1016/j.jtcvs.2011.12.005
}

contraindicates the procedure. Bleiziffer and colleagues ${ }^{2}$ reported that 1 year after transapical TAVI, a new apical hypo- or akinesia was present in up to $37 \%$ of patients, and that because of the apical scar, a significant reduction of the LV ejection fraction was found in $13 \%$ of patients. In these patients with "no access," a subclavian/axillary approach has been described, ${ }^{3}$ but it is not feasible in case a $29-\mathrm{mm}$ device is necessary or both subclavian arteries are heavily calcified or extremely tortuous. A transaortic implantation has been described using the CoreValve revalving system. ${ }^{4}$ We describe the technique for $29-\mathrm{mm} \mathrm{Sa}$ pien XT implantation via a transaortic access.

\section{CLINICAL SUMMARY}

A 70-year-old man with severe symptomatic aortic valve stenosis was admitted to the University of Padova for acute pulmonary edema. His aortic valve area was $0.74 \mathrm{~cm}^{2}$, peak and mean gradients were 38 and $21 \mathrm{~mm} \mathrm{Hg}$, respectively, LV ejection fraction was $22 \%$, and end-diastolic volume index was $118 \mathrm{~mL} / \mathrm{m}^{2}$. In this patient, the nature of LV dysfunction was related to the chronic occlusion of the right coronary artery with a consequent akinesia of the 